\title{
PROPOSALS FOR IMPROVING THE TECHNOLOGICAL PROCESSES OF WATER CIRCULATION, WASTE PROCESSING AND QUALITY ASSESSMENT
}

\author{
1'Daria STRAPOLOVA, ' Kamila JANOVSKÁ, 'S Sofiya SHEVTSOVA, ${ }^{2}$ Viktoriia STRAPOLOVA, \\ ${ }^{3}$ Evgenii KUZIN, ${ }^{4}$ Petr OČKO
}

${ }^{1}$ VSB - Technical University of Ostrava, Ostrava, Czech Republic, EU, daria.strapolova.st@vsb.cz, kamila.janovska@vsb.cz, sofiya.shevtsova.st@vsb.cz

${ }^{2}$ Kompozite Ltd. Korolev, Russia, v.n.strapolova@mail.ru

${ }^{3}$ MUCTR, Moscow, Russia, e.n.kuzin@muctr.ru

${ }^{4}$ Silesian University in Opava, Czech Republic, ocko@mpo.cz

https://doi.org/10.37904/metal.2021.4288

\begin{abstract}
Within the framework of this work, a typical technology with subsequent assessment of the quality of production processes of titanium alloy powder and products made from it was evaluated. A comprehensive analysis of the production process was carried out from the production of a metal billet to the creation of a powder material and the formation of the final product. The processes was identified to improve to simplify the operation of the system and reduce cost.

The main difficulties (frequent problems) that are regularly encountered by both the manufacturer and the consumer of products of additive technology and powder metallurgy are described. Analyzing the standard technology, we can say that it is necessary to improve the water circulation system in the enterprise, improve the system of waste collection and disposal, as well as develop a simplified algorithm for finding and selecting equipment in this industry. The measures to simplification production processes are presented in this article. These are beneficial changes from an economic point of view. And they are also environmentally friendly methods of optimizing production, since the work describes the use of natural resources and methods of secondary processing with minimal utilization disposal.
\end{abstract}

Keywords: Additive technologies, powder metallurgy, optimization

\section{INTRODUCTION}

Growth in industrial production is continuously accelerating. The metallurgical industry is no exception and occupies a leading position in the development of "Industry 4.0". As new metallurgical technologies appear on the market, we can observe a departure from traditional metallurgical processes. These technologies include powder metallurgy processes [1]. Innovation in this area is helping to drive the creation of products with complex configurations [2]. The demand for additive production and therefore also materials obtained in the process of powder metallurgy is growing every year. According to data for 2019, demand in Europe for machinery used in these technologies has increased by $36 \%$ [3]. It is therefore important to remain up to date on new scientific and technical solutions which appear in this segment of industry every year. Analyses have highlighted the problems existing in the water circulation systems of companies and the need to improve systems of waste collection and disposal during powder metallurgy processes. The paper proposes measures for optimizing the algorithm applied to innovative water turnover processes, material processing and quality evaluation. These are proposals for changes which could have a significant effect on the costs related to powder metallurgy processes. 


\section{METHODOLOGICAL BASES}

For a full and high-quality analysis of the basic issues of additive production, it is first necessary to study and characterize in detail the individual phases of the technological chain of acquisition and application of materials. The algorithm for multiple products with complex configurations is a group of processes which include traditional processes of melting semi-finished metal products, developing and obtaining the chemical composition of materials, and the combination of powders and their subsequent formation into finished products [4]. The use of titanium powder-based alloys has become widespread. The choice of material is primarily influenced by its extremely high operating properties (strength), low weight (lightness) and a high degree of resistance to corrosion. The chemical composition of alloys in the production of various products is determined by the conditions the alloy is used under, the geometry and assignment of the part, and reliability and durability requirements. The main methods of powder production include PREP (Plasma Rotating Electrode Process) [5], EIGA (European Inert Gas Atomization), VIGA (Vacuum Inert Gas Atomization), gas or centrifugal spraying, and water atomization. The properties of the powder depend directly on the quality of the original metal ingot/rod produced in traditional metallurgical processes. The key requirements in the original raw material are surface uniformity and its chemical composition. The current main industrial method of production of titanium alloys is triple vacuum arc remelting [6]. The basis of the most common production technology for metal powders ( $80 \%$ of the total production of powders) for the needs of the additive industry is the melt dispersion method. The main advantages of this method are high performance, preservation of the chemical composition in the semi-product-powder phase, and the possibility of using multiple powders and their geometric properties (we aim for a spherical shape). The main production technologies for these powders are gas and centrifugal atomization [2].

The analytical study investigated the current system of powder metallurgy and use of powders in engineering production.

The following areas of powder metallurgy processes were identified for improvement:

1) Water turnover system in production.

2) System of capture and recovery of production waste.

3) Development of an algorithm to identify and select equipment to expand or modernize production.

\section{EXPERIMENTAL PART}

\subsection{Improvement of the water turnover system in production}

Powder metallurgy processes involve the consumption of significant volumes of fresh water, primarily for cooling technological equipment (spraying equipment, etc.) and cleaning dusty waste gases, but include the consumption of very pure water for water atomization in metal powder production facilities. The process of producing powders using plasma heating is carried out at extremely high temperatures (above $+1168{ }^{\circ} \mathrm{C}$ ), and therefore a large quantity of cooling water is required. To minimize the effects of salts and corrosion, water for production use must undergo multi-stage treatment and have a minimum salt content [7]. The primary sources of industrial water supply to plants are via centralized water mains or from artesian wells. Water supplied for cooling remains practically untreated and is discharged into the sewer system. High iron content (corrosion) and salt stiffness (lime scale) can lead to damage to technological equipment. Metal losses due to corrosion can reach $12 \%$ by weight [8], and according to the average assessments of damage due to corrosion, accident or equipment failure (repairs), a company's combined costs may reach approximately $3.1-4.4 \%$ of profits. Similar problems concerning wastewater generation are associated with gas purification processes. Water from wastewater treatment plants is used only once and drained to the sewer without appropriate treatment. The only true solution aimed at optimizing production is the introduction of water preparation technology for thermal engineering needs (primary treatment and release), and organization of the cycle of water treatment 
and wastewater turnover from waste gas cleaning equipment. This then creates a closed water management system. The analyses performed at selected companies in Russia revealed that the application of (coagulation) treatment using reactants in these processes can reduce water consumption at their facilities by approximately $5-10 \%$. Therefore, a reduction in the consumption of fresh water and the volume of wastewater generated by powder metallurgy processes would have beneficial economic effects. Another possible direction for Improvement is streamlining the system of collection and use of atmospheric precipitation. The chemical composition of atmospheric precipitation is given in Table 1.

Table 1 Chemical composition of atmospheric precipitation

\begin{tabular}{|c|c|c|c|c|c|}
\hline \multirow{2}{*}{ Indicator } & \multirow{2}{*}{$\begin{array}{c}\text { Unit of } \\
\text { measure }\end{array}$} & \multicolumn{2}{|c|}{ Atmospheric precipitation } & \multirow{2}{*}{ Tap water } & $\begin{array}{c}\text { Maximum } \\
\text { threshold value } \\
\text { (requested by } \\
\text { manufacturers) }\end{array}$ \\
\cline { 3 - 5 } & & $\begin{array}{c}\text { Spring- } \\
\text { Summer }\end{array}$ & $\begin{array}{c}\text { Autumn- } \\
\text { Winter }\end{array}$ & & 1 \\
\hline Stiffness & mg-EQ./I & 0.2 & 0.22 & $6.0-7.0$ & 400 \\
\hline Total mineralization & $\mathrm{Mg} / \mathrm{I}$ & 40.13 & 21.92 & $500-700$ & 1.5 \\
\hline Substances in suspension & $\mathrm{Mg} / \mathrm{I}$ & 1.92 & 1.51 & $0.9-1.4$ & 1.4 \\
\hline
\end{tabular}

Precipitation data for the year in the Moscow region is given in Figure 1.

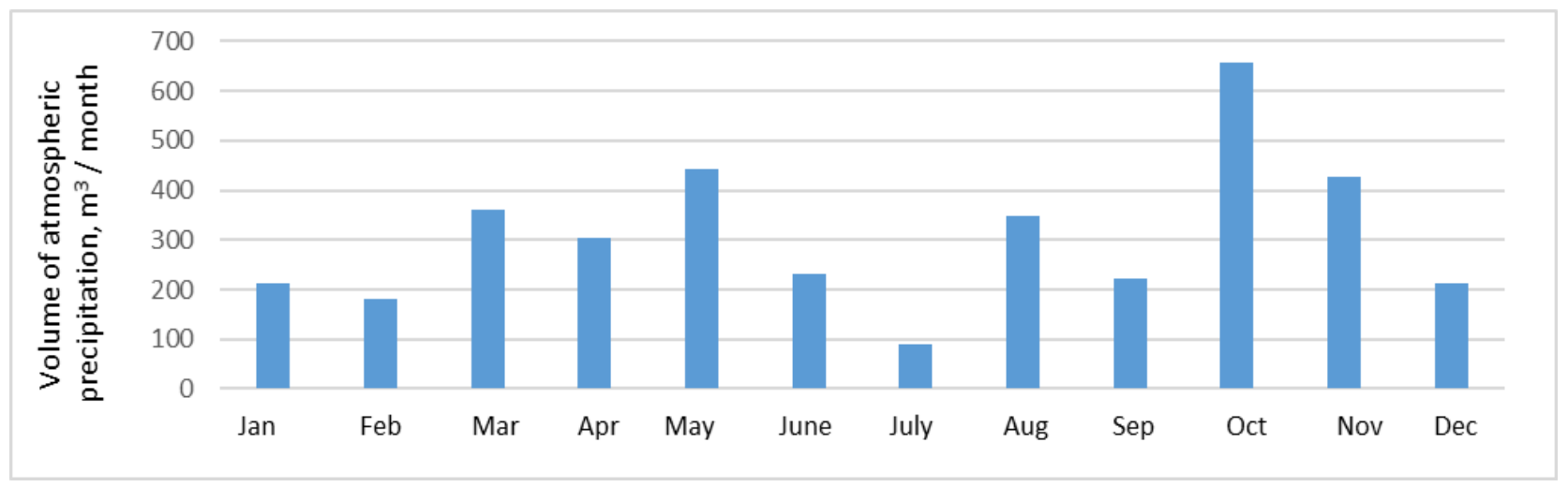

Figure 1 Precipitation during the monitored period in the Moscow region

From the data in Table 1, we can observe that compared to tap water, atmospheric precipitation requires virtually no treatment and can be used for cooling purposes after conventional mechanical filtration. The documentation of selected companies in the Moscow region showed that medium-sized companies have closed water turnovers of around $600 \mathrm{~m} 3$ per month. Was performed various calculations working with different types of water usage (ratio of rainwater/well water/tap water) and found that replacement of a volume of 400 m3 per month of tap water with rainwater would result in a reduction of water consumption costs in the powder metallurgy process by $60-66 \%$ on average (average of EUR 100 per month).

\subsection{System of capture and recovery of production waste}

In general, additive technology is considered waste-free production, but a detailed examination revealed some nuances. In the process of centrifugal or gas spraying, the metallic degree of use of the original raw material (rods, wires, ingots) never achieves $100 \%$. The undissolved part (ogarok) makes up $20-30 \%$ of the original raw material and is directed toward mixed metal waste production. According to an estimate, the amount of unconventional (particle) size can reach 30 to $40 \%$ of the total installed capacity [9]. Was performed detailed analyses at selected companies in Russia and found that during the gas cleaning processes in the above operations, the loss is up to $5 \%$ of the total volume of powder produced. The removed particles are stored 
without a protective atmosphere, and for this reason, cannot be used as Ti powder and are instead directed to waste. Based on their analyses of the literature [10,11], was formulated a concept for processing the data on waste relating to the acquisition of commodity products. During heat treatment in an oxygen stream (on existing equipment) when these powder wastes are specifically obtained, it is possible to obtain titanium dioxide which can be used as an additive in coating materials and various other uses (manufacturing of paper and pigments, in rubber engineering, plastics processing, etc.). The proposed methods which address the issue of recycling and processing Ti powder would not only result in a reduction of the volume of waste but also produce a product which can be sold to specialized organizations. In an example of the calculation of the economic effects in a system of capture and recovery of production waste, was assumed, as a starting point, that $100 \%$ of the source material has a mass of $107.500 \mathrm{~kg}$. In the process of obtaining the powder, a portion of the material is not exposed to melting. This value is usually about $30 \%$ of the original material, i.e., the unmelted portion has a mass of $32.250 \mathrm{~kg}$. The resultant mass of the Ti powder is $75.250 \mathrm{~kg}$. In separating the powder according to size and removing slag particles, $5 \%$ is lost, i.e., $3.765 \mathrm{~kg}(75.250 * 5 / 100=3.765)$. A total of $71.480 \mathrm{~kg}$ of the actual powder remains. A diagram of the percentage size distribution (Figure 3) shows that the working fraction (powder for additive production for sale) is about $70 \%$. Therefore, the powder not used in production is $30 \%$ by mass of the initial powder, i.e., $21.440 \mathrm{~kg}(71.480 * 30 / 100=21.440)$.

As output, we obtain:

- $\quad$ Required mass of Ti powder for sale $50.040 \mathrm{~kg}$

- $\quad$ Mass of unmelted portion $32.250 \mathrm{~kg}$ (sold at the price of metal)

- Mass of unusable powder is $25.205 \mathrm{~kg}$ (sold at the price of titanium dioxide)

The distribution of particles proceeds according to the empirical data shown in Figure 2. The working fraction is given by the most common range of use of the powder in an additive manufacturing plant.

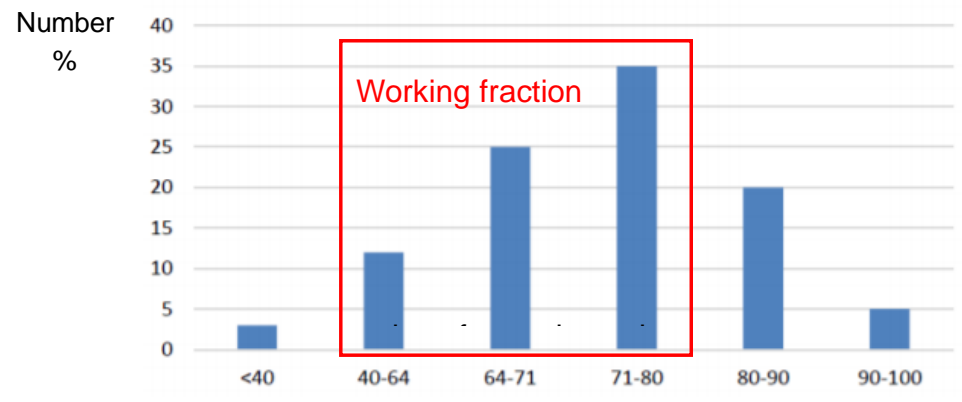

Figure 2 Separation of powder into fractions in percentage ratio

\subsection{Development of an algorithm to identify and select equipment to expand or modernize production in powder metallurgy processes}

In launching new production facilities or modernizing existing powder metallurgy plants, manufacturers must address the problem of selecting suitable equipment according to set criteria. The paper to devised a technique to assist in the selection of a suitable technological equipment based on a weighted qualitative evaluation of the equipment according to expert (specialists) recommendations from selected companies was presented.

The main characteristic of the method in determining the weighting coefficients is the compilation of a list of the most important parameters and subsequent summary of preferences by selected expert advisors (12 experts). Table 3 shows six key indicators and fifteen parameters essential in evaluating the equipment for powder metallurgy at the selected companies. 
Table 3 Proposed priority selection method according to a comparison of individual indicators: productivity, performance, material versatility, direct costs, price, product output

\begin{tabular}{|c|c|c|c|c|c|c|c|}
\hline & & 1 & 2 & 3 & 4 & 5 & 6 \\
\hline & & Productivity & $\begin{array}{l}\text { Perfor- } \\
\text { mance }\end{array}$ & $\begin{array}{c}\text { Material } \\
\text { versatility }\end{array}$ & Direct costs & Price & Product output \\
\hline 1 & $\begin{array}{l}\text { Produc- } \\
\text { tivity }\end{array}$ & * & $\begin{array}{l}\text { Priorita } \\
\text { productivity } \\
\text { or } \\
\text { performance } \\
1 \text { or } 2\end{array}$ & $\begin{array}{l}\text { Priorita } \\
\text { productivity or } \\
\text { material } \\
\text { versatility } 1 \text { or } 3\end{array}$ & $\begin{array}{l}\text { Priorita } \\
\text { productivity } \\
\text { or direct cost } \\
1 \text { or } 4\end{array}$ & $\begin{array}{l}\text { Priorita } \\
\text { productivity } \\
\text { or price } \\
1 \text { or } 5\end{array}$ & $\begin{array}{l}\text { Priorita } \\
\text { productivity or } \\
\text { product output } \\
1 \text { or } 6\end{array}$ \\
\hline 2 & $\begin{array}{l}\text { Perfor- } \\
\text { mance }\end{array}$ & * & * & $\begin{array}{l}\text { Priorita } \\
\text { performance or } \\
\text { material } \\
\text { versatility } \\
2 \text { or } 3\end{array}$ & $\begin{array}{l}\text { Priorita } \\
\text { performance } \\
\text { or direct } \\
\text { costs } \\
2 \text { or } 4\end{array}$ & $\begin{array}{l}\text { Priorita } \\
\text { performance } \\
\text { or price } \\
2 \text { or } 5\end{array}$ & $\begin{array}{l}\text { Priorita } \\
\text { performance or } \\
\text { product output } \\
2 \text { or } 6\end{array}$ \\
\hline 3 & $\begin{array}{c}\text { Material } \\
\text { versatility }\end{array}$ & * & * & * & $\begin{array}{l}\text { Priorita } \\
\text { material } \\
\text { versatility or } \\
\text { direct costs } \\
3 \text { or } 4\end{array}$ & $\begin{array}{l}\text { Priorita } \\
\text { material } \\
\text { versatility or } \\
\text { price } \\
3 \text { or } 5\end{array}$ & $\begin{array}{l}\text { Priorita material } \\
\text { versatility or } \\
\text { product output } \\
3 \text { or } 6\end{array}$ \\
\hline 4 & $\begin{array}{l}\text { Direct } \\
\text { costs }\end{array}$ & * & * & * & * & $\begin{array}{l}\text { Priorita direct } \\
\text { costs or price } \\
4 \text { or } 5\end{array}$ & $\begin{array}{l}\text { Priorita direct } \\
\text { costs or product } \\
\text { output } \\
4 \text { or } 6\end{array}$ \\
\hline 5 & Price & * & * & * & * & * & $\begin{array}{l}\text { Priorita price or } \\
\text { product output } \\
5 \text { or } 6\end{array}$ \\
\hline 6 & $\begin{array}{l}\text { Product } \\
\text { output }\end{array}$ & * & * & * & * & * & * \\
\hline
\end{tabular}

The weight coefficient for the "Productivity" indicator is $12 / 15=0.80$. This weight ratio is taken into account in calculating the Qualimetry Rating of the device (e.g., arithmetic mean); the final value of this parameter is $80 \%$. The obtained value can be replaced as a priority parameter in one of the classic qualometric estimation formulas [12].

\section{CONCLUSION}

The paper evaluates existing additive production facilities using an engineering company as an example. The evaluation included an analysis of powder metallurgy processes, specifically organization of the water cycle to reduce the cost of water treatment and also minimize the subsequent penalties issued by water management authorities for the discharge of insufficiently treated wastewater. The various calculations working with different types of water usage and subsequently quantified the average value of cost reduction related to water consumption in the powder metallurgy process was performed.

Another factor in improvements the powder metallurgy process is arrangement of the order of collection, operation and utilization of waste generated during production. During the operation of production facilities and as a result of the quality requirements for the produced powders, companies can generate a significant amount of waste. The paper describes the system of capture and recovery of production waste. The last phase of improvement addressed by in this paperis the technique of qualimetric (balanced) selection of new or 
modernized additive production equipment and presentation of a method of priority selection, which compares individual indicators for simplification the process, and expand the availability of additive production.

\section{ACKNOWLEDGEMENTS}

The work was supported by the specific university research of the Ministry of Education, Youth and Sports of the Czech Republic in VSB - Technical University of Ostrava No. SP2021/43 and SP2021/71.

\section{REFERENCES}

[1] NOVÁK, P. Advanced Powder Metallurgy Technologies. Materials. [online]. 2020, vol. 13, no. 7, pp. 1-3. Available from: https://doi.org/10.3390/ma13071742.

[2] ZLENKO, M. A., POPOVICH, A. A., MUTYLINA, I. N. Additive technologies in mechanical engineering. St. Petersburg Polytechnic University Press. 2013, pp. 1-7.

[3] WIMBERT, L., HÖGES, S., SCHNEIDER, M., TILLER, S. Powder metallurgy in Germany. International Journal of Powder Metallurgy. 2020, vol. 56, no. 2, pp. 37-41.

[4] VLASOVA, T. Eco-friendly additive technologies in construction: an overview. Engineering Bulletin of the Don. 2019, vol. 6, no. 57, pp. 21-28.

[5] RUDSKOI, A.I., SOKOLOV, YU.A., KOPAEV, V.N. Specifics of modelling of the process of receiving granules by prep method, Metallurgy. 2015, pp.123-129.

[6] MIR, H. E., JARDY, A., BELLOT, J.-P., CHAPELLE, P., LASALMONIE, D., SENEVAT, J. Thermal behaviour of the consumable electrode in the vacuum arc remelting process. Journal of Materials Processing Technology. [online]. 2010, vol. 210, no. 3, pp. 564-572. Available from: https://doi.org/10.1016/i.jmatprotec.2009.11.008.

[7] GOST 20995-75. Standard adopted by the standardization body of a member state of the Eurasian Economic Union. Stationary steam boilers. Moscow: IPK Publishing House of Standards, 2003

[8] KRASNAYA E. G., TARANTSEVA K. R., FIRSOVA O. V. Assessment of environmental damage due to corrosion destruction of equipment. In: Innovations: collection of articles of the XI International Scientific and Practical Conference internet. Penza, Russia: Penza State Technological Academy, 2015.

[9] MUSIENKO V.T. Regularities of granule formation during centrifugal spraying of a rotating billet. Moscow: VILS Publishing House, 1983.

[10] KHAZIN, L.G., Titanium Dioxide, Leningrad: Khimiya, 1970.

[11] BELENKY, E. F., RISKIN, I. V. Chemistry and technology of pigments. Leningrad, Goskhimizdat, 1960.

[12] ZHUMAHANOVNA, B. Z., SEKENOVICH, O. B., TAINIGAZJEVICH, B. A. The Development of Rational Qualimetric Characteristic of Progressive Method the Estimation of Reproduction Quality of Topographic and Map Production. Procedia - Social and Behavioral Sciences. [online]. 2014, vol. 141, pp. 1373-1377. Available from: https://doi.org/10.1016/..sbspro.2014.05.237. 